\title{
Optical and structural characteristics of strontium doped calcium tartrate crystals
}

\author{
K SURYANARAYANA*, S M DHARMAPRAKASH and K SOORYANARAYANA ${ }^{\dagger}$ \\ Department of Physics, Mangalore University, Mangalagangotri 574 199, India \\ 'Solid State and Structural Chemistry Unit, Indian Institute of Science, Bangalore 560012 , India
}

MS received 17 April 1997

\begin{abstract}
We report here on the optical and structural characteristics carried out on strontium doped calcium tartrate tetrahedral single crystalline materials obtained by diffusing calcium and strontium ions through silica gel impregnated with optically active tartaric acid. Linear optical properties of this material such as refractive index, birefringence and transmission characteristics were measured in the wavelength range $200 \mathrm{~nm}<\lambda<1500 \mathrm{~nm}$. No dispersion of the birefringence was observed within the experimental accuracy. The packing of tartrate molecules remained unaltered with $12 \%$ of the strontium doping.
\end{abstract}

Keywords. Silica gel; refractive index; crystal structure; second harmonic generation.

\section{Introduction}

Single crystals of calcium tartrate (CT) and strontium tartrate (ST) have attracted considerable attention in recent years on account of their ferroelectric, non linear optical and spectral characteristics (Medrano et al 1987; Brehat and Wyncke 1989; Nakatani 1991; Selvarajan et al 1993; Rethinam et al 1994). CT and ST crystallize in the orthorhombic system with space group $P 2_{1} 2_{1} 2_{1}$ having four molecules in the elementary unit cell (Ambady 1968; Bohandy and Murphy 1968). In the course of our investigations on the physical properties of CT and ST our attention was drawn to the growth and characterization of strontium doped calcium tartrate (CST). This work was undertaken to study the optical characteristics and effect of doping on the structural role of tartrate ion in the presence of two divalent metallic elements.

\section{Experimental}

\subsection{Growth and crystal habit}

The strontium doped calcium tartrate single crystals employed for optical and X-ray diffraction studies were grown by the silica gel method. The growth process involves the controlled diffusion of calcium chloridestrontium chloride solutions into gel made up of sodium metasilicate and tartaric acid (all AR grade) solutions at constant temperature and visible light conditions. The experiment was performed in Corning glass tubes of length $200 \mathrm{~mm}$ and inner dia. $25 \mathrm{~mm}$. The suitable conditions for the growth of the best quality CST single

*Author for correspondence crystals were: $\mathrm{pH} 3 \cdot 5-4 \cdot 0$, gelling time 12 days, concentration of the reactants $1.0 \mathrm{M}$ and growth temperature $30^{\circ} \mathrm{C}$. Growth of CST crystals (about $10 \times 6 \times 4 \mathrm{~mm}^{3}$ in size) was observed down the gel column in the experimental vessels within a week. During the exchange reaction $\mathrm{HCl}$ yielded as a byproduct. The crystal size and time of formation of ST depend on the density of the gel and concentration of the supernatent solutions. The gel grown CST single crystals were colourless and optically transparent. Qualitative chemical analyses using an energy dispersive X-ray spectrometer (EDX) confirmed that the single crystals are those of CST in which two alkaline earths form solid solution in the ratio $0 \cdot 88: 0 \cdot 12$. The maximum uptake of strontium in the CST crystal depends on the molarity of the mixed calcium chloride and strontium chloride solutions with different ratios. The crystals grown were confirmed to have the composition $\mathrm{Ca}_{0.88} \mathrm{Sr}_{0 \cdot 12} \mathrm{C}_{4} \mathrm{H}_{4} \mathrm{O}_{6} \cdot 4 \mathrm{H}_{2} \mathrm{O}$ under the above mentioned growth conditions. The single crystalline habit of CST is deviated from the habit of CT and ST single crystals (figure 1). The crystals are elongated in the b-direction and the principal faces are (110), (010) and (011) with their symmetry equivalents.

\subsection{Structure}

The crystal thus grown was transparent and was mounted on the X-ray diffractometer after confirming the quality by examining under a polarizing microscope. The intensity data were collected on an Enraf-Nonius CAD4 diffractometer having graphite monochromated $\mathrm{MoK} \alpha$ radiation $(\lambda=0.7107 \AA)$ in the $\omega / 2 \theta$ mode. The cell parameters were obtained from the least square refinement of 25 reflections $(-231,-130,03-1)$ after every $3600 \mathrm{~s}$ 
of exposure time; the orientation was checked every 400 reflections and no significant fluctuations in their intensity were observed. The data was corrected for Lorenz and polarization effects but not for absorption effect since it is negligible. The structure of strontium doped calcium tartrate tetrahydrate was solved using SHELXS 86 (Sheldrick 1985). The heavy atoms were located using Patterson method and the rest of the structure was developed using partial structure expansion technique. The structure refinement was carried out using SHELX 93 (Sheldrick 1993). Hydrogen atoms were located from the difference map. All nonhydrogen atoms were refined anisotropically. The details of crystal data and refinement results are given in table 2.

\section{Results and discussion}

\subsection{UV-visible spectrum of CST single crystals}

Optical absorption measurements for CST single crystal

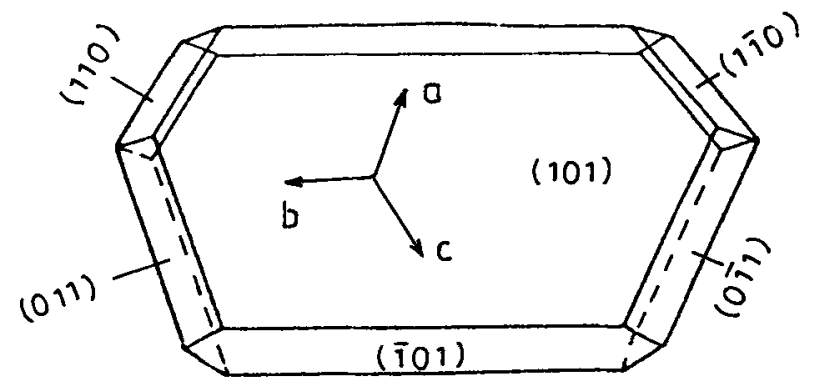

(a)

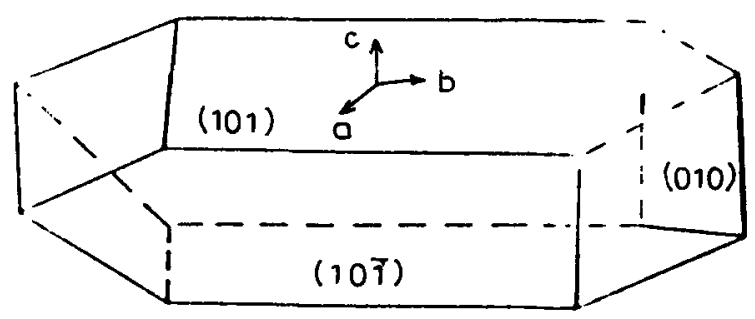

(b)

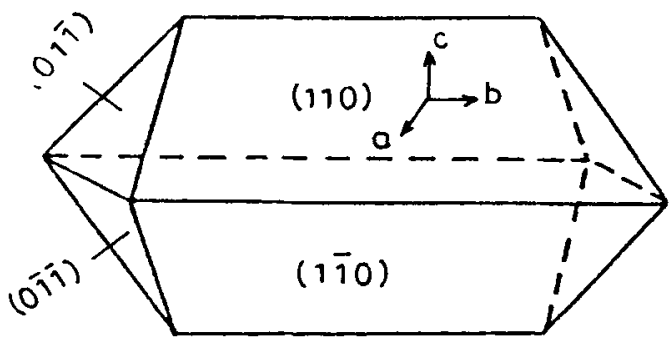

(c)

Figure 1. Habit of (a) calcium tartrate, (b) strontium tartrate and (c) strontium doped calcium tartrate single crystals. with thickness $1.0 \mathrm{~mm}$ were performed with a Cary-14 spectrophotometer in the range $200-1400 \mathrm{~nm}$ at room temperature. No absorption decreasing film was coated on the surfaces of the crystal and the light loss caused by reflections on the surfaces was ignored. The absorption coefficient as a function of wavelength, was evaluated. Anisotropy was observed for different light directions. One can see from figure 2 that the single crystals of CST are transparent in the range $275-1325 \mathrm{~nm}$ and the transmittivity is greater than $85 \%$. The optical transmission range as determined from the optical characteristics, makes the CST crystal interesting for second harmonic generation in the ultra violet region.

\subsection{Linear optical properties}

According to the crystal system three planes normal to the three orthorhombic unit cell axes with $x, y, z$ parallel

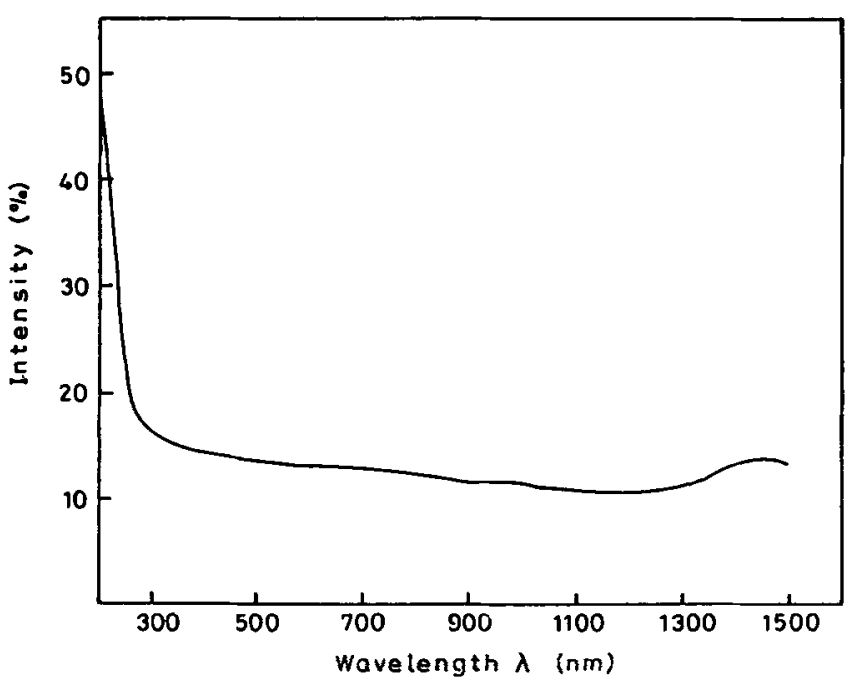

Figure 2. UV visible spectra of strontium doped calcium tartrate single crystal (thickness, $1.0 \mathrm{~mm}$ ).

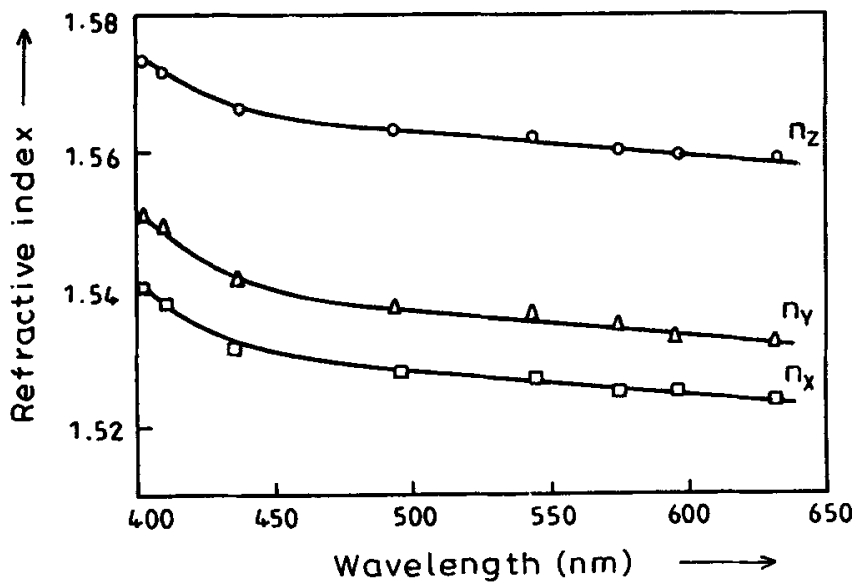

Figure 3. Dispersion of the principal refractive indices of strontium doped calcium tartrate single crystal at room temperature. 
to the crystallographic $\mathrm{a}, \mathrm{b}$ and $\mathrm{c}$ axes, respectively, were prepared to determine birefringence and refractive indices. The refractive index of the crystal within the visible light range was measured by the Brewster's angle method

Table 1. Linear optical data of CST single crystals.

\begin{tabular}{lcccccc}
\hline & \multicolumn{3}{c}{ Refractive indices } & & \multicolumn{2}{c}{ Birefringence } \\
\cline { 2 - 3 } \cline { 6 - 7 }$\lambda(\mathrm{nm})$ & $n_{\mathrm{x}}$ & $n_{\mathrm{y}}$ & $n_{\mathrm{z}}$ & & $\Delta n_{\mathrm{x}}$ & $\Delta n_{\mathrm{z}}$ \\
\hline 405 & 1.5398 & 1.5514 & 1.5738 & & 0.02 & 0.03 \\
408 & 1.5383 & 1.5501 & 1.5726 & & 0.02 & 0.03 \\
436 & 1.5316 & 1.5431 & 1.5661 & & 0.02 & 0.03 \\
492 & 1.5292 & 1.5392 & 1.5639 & & 0.02 & 0.03 \\
546 & 1.5272 & 1.5378 & 1.5632 & & 0.02 & 0.03 \\
577 & 1.5255 & 1.5356 & 1.5611 & & 0.02 & 0.03 \\
589 & 1.5243 & 1.5344 & 1.5589 & & 0.02 & 0.03 \\
633 & 1.5229 & 1.5336 & 1.5567 & & 0.02 & 0.03 \\
\hline
\end{tabular}

Table 2. Crystal data and structural refinement.

\begin{tabular}{|c|c|}
\hline Empirical formula & $\mathrm{Ca}_{0.876} \mathrm{Sr}_{0.124} \mathrm{C}_{4} \mathrm{H}_{12} \mathrm{O}_{10}$ \\
\hline Formula weight & $266 \cdot 11$ \\
\hline Crystal size (in $\mathrm{mm}$ ) & $0.41 \times 0.12 \times 0.18$ \\
\hline Crystal system & Orthorhombic \\
\hline Space group & $P 2,2_{1} 2_{1}$ \\
\hline $\begin{array}{l}\text { Unit cell dimensions } \\
\text { a } \\
\text { b } \\
\mathbf{c}\end{array}$ & $\begin{array}{r}9.231(2) \AA \\
9 \cdot 619(4) \AA \\
10 \cdot 610(5) \AA\end{array}$ \\
\hline Volume & $942 \cdot 2(6) \AA^{3}$ \\
\hline $\begin{array}{l}Z \text { (number of molecules } \\
\text { per unit cell) }\end{array}$ & 4 \\
\hline$F(000)$ & 576.0 \\
\hline Density (calc) & $1.875 \mathrm{~g} / \mathrm{cm}^{3}$ \\
\hline Radiation used & $\operatorname{Mo~K\alpha }(\lambda=0.7107 \AA)$ \\
\hline Diffractometer & Enraf-Nonius CAD4 \\
\hline $\begin{array}{l}\text { Diffraction measurement } \\
\text { method }\end{array}$ & $\omega / 2 \theta$ \\
\hline Reflections collected & 2284 \\
\hline Unique reflections & 2027 \\
\hline $2 \theta$ range & $2.86^{\circ}$ to $26.97^{\circ}$ \\
\hline$h, k, l$ range & $\begin{aligned}-11 & \leq h \leq 11 \\
0 & \leq k \leq 12 \\
0 & \leq l \leq 13\end{aligned}$ \\
\hline Refinement method & $\begin{array}{l}\text { Full matrix least squares } \\
\text { on } F^{2}\end{array}$ \\
\hline Goodness of fit on $F^{2}$ & $1 \cdot 587$ \\
\hline $\begin{array}{l}\text { Final } R \text { indices } \\
\quad(I>2 \sigma(I))\end{array}$ & $R=0.087, w R=0.233$ \\
\hline$R$ indices (all data) & $R=0.152, w R=0.268$ \\
\hline $\begin{array}{l}\text { Residual electron } \\
\text { density }\end{array}$ & $\begin{array}{l}\max =0.83 \mathrm{e} / \AA^{3} \\
\min =-0.58 \mathrm{e} / \AA^{3}\end{array}$ \\
\hline
\end{tabular}

(figure 3). The data are listed in table 1. The quality of the crystal together with the low birefringence of this material led to a precise measurement with an accuracy of \pm 0.005 . The wavelength dependence of the birefringence was determined by using a monochromator, mercury lamp, sodium lamp and $\mathrm{He}-\mathrm{Ne}$ laser as light source for the polarizing microscope. The birefringence is independent of the wavelength in the wavelength range $400-650 \mathrm{~nm}$.

CST belongs to one of the four acentric orthorhombic point groups, determined by the convention that the principal refractive indices are such that $n_{z}>n_{y}>n_{x}$, which implies that in CST crystal the optical plane is the $x-z$ plane. Results on the dispersion of the indices of refraction show that CST is an optically positive biaxial crystal.

\subsection{Non linear optical properties}

The second harmonic generation experiments were performed with an unfocussed and linearly polarized, Nd : YAG laser $(\lambda=1.064 \mu \mathrm{m})$. CST crystal exhibits small optical nonlinearity. The second harmonic generation intensity of CST is 0.1 times that of quartz. Limited by the experimental condition, the nonlinear optical coefficients of CST single crystal have not been obtained.

\subsection{Structure}

There is no significant structural change in the CST

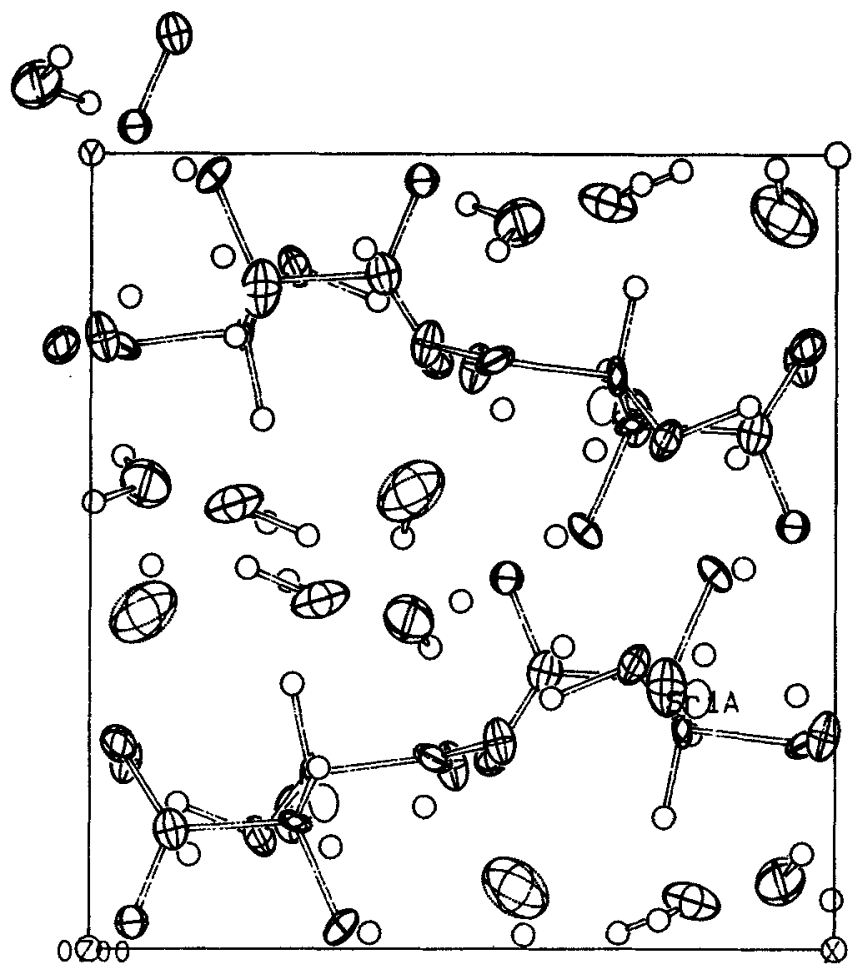

Figure 4. The strucure of strontium doped calcium tartrate single crystal. 


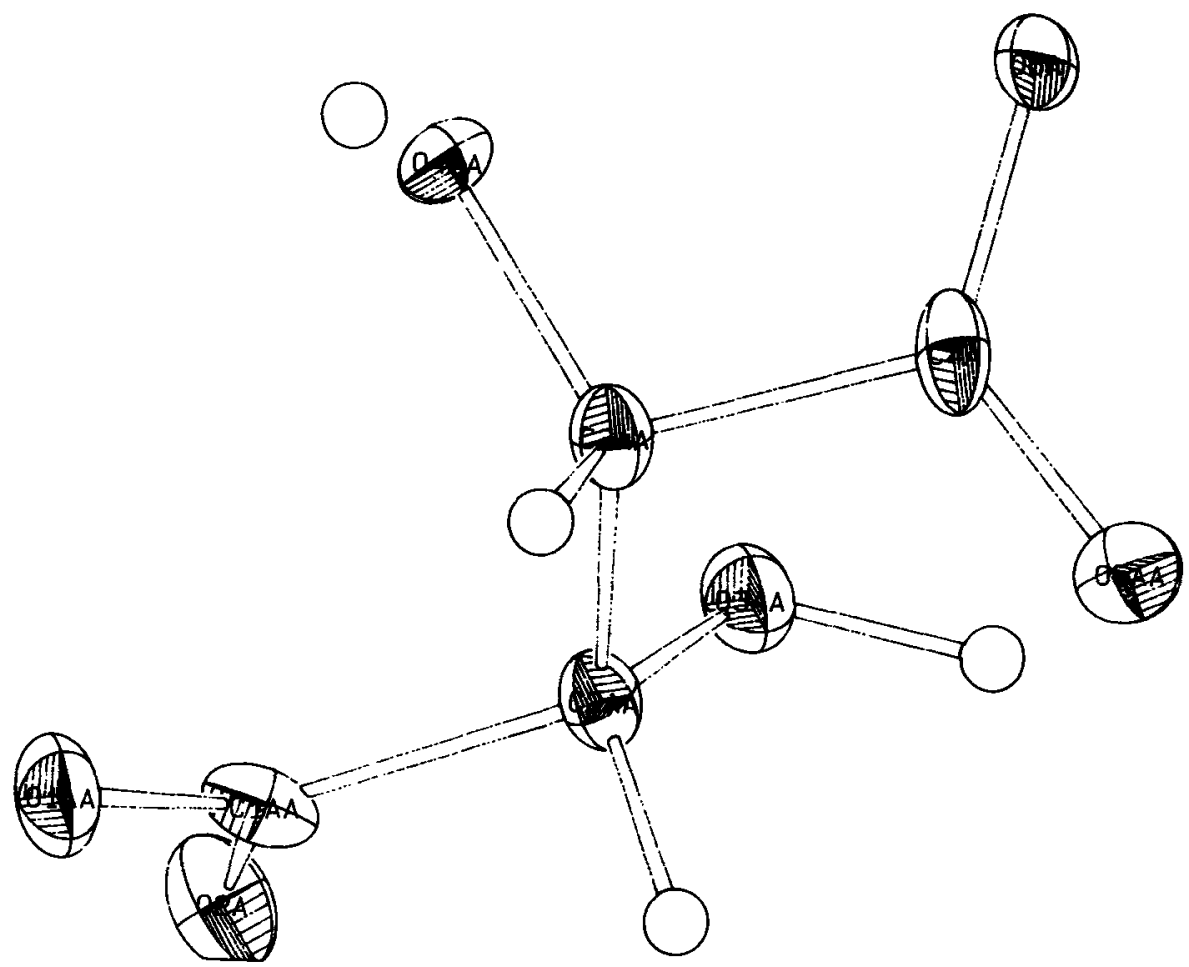

Figure 5. The details of the tartrate molecule.

Table 3. Atomic coordinates, occupancy and $U_{\text {eq. }}$.

\begin{tabular}{|c|c|c|c|c|c|}
\hline & $x / a$ & $y / b$ & $z / c$ & Occupancy & $U_{\mathrm{eq}}$ \\
\hline $\mathrm{Sr}$ & $0.1864(2)$ & $0.8160(2)$ & $0.8218(2)$ & $0 \cdot 124$ & $171(4)$ \\
\hline $\mathrm{Ca}$ & $0 \cdot 1864(2)$ & $0.8160(2)$ & $0.8218(2)$ & 0.876 & 171(4) \\
\hline 01 & $0.4507(8)$ & $0.7617(8)$ & $0.8086(8)$ & 1.000 & $209(1)$ \\
\hline 02 & $0.0153(8)$ & $0.7688(9)$ & $0.9920(9)$ & 1.000 & $273(6)$ \\
\hline 03 & $0.7717(8)$ & $0.6415(8)$ & $0.9517(8)$ & 1.000 & 198(6) \\
\hline 04 & $0.6627(8)$ & $0.5273(8)$ & $0.7168(8)$ & 1.000 & $219(0)$ \\
\hline 05 & $-0.0389(8)$ & $0.7583(9)$ & $0.7143(8)$ & 1.000 & $222(8)$ \\
\hline 06 & $0.0573(8)$ & $1.0334(7)$ & $0.8275(9)$ & 1.000 & $221(4)$ \\
\hline 07 & $0.1928(12)$ & $0.5604(9)$ & $0.8296(13)$ & 1.000 & $552(6)$ \\
\hline 08 & $-0.0732(11)$ & $1.0854(10)$ & $1.0702(10)$ & 1.000 & $404(0)$ \\
\hline 09 & $0.2269(9)$ & $0.8309(11)$ & $0-5877(8)$ & 1.000 & $329(8)$ \\
\hline 010 & $0.4285(14)$ & $0.5763(12)$ & $0.5668(12)$ & 1.000 & $624(6)$ \\
\hline $\mathrm{Cl}$ & $0.5407(12)$ & $0.7405(11)$ & $0.8927(11)$ & $1 \cdot 000$ & $200(0)$ \\
\hline $\mathrm{C} 2$ & $0.7049(11)$ & $0.7216(11)$ & $0.8612(10)$ & 1.000 & $172(4)$ \\
\hline $\mathrm{C} 3$ & $0.7245(11)$ & $0.6604(10)$ & $0.7293(10)$ & 1.000 & 119(9) \\
\hline $\mathrm{C} 4$ & $0 \cdot 1095(11)$ & $1 \cdot 1503(11)$ & $0.7979(11)$ & 1.000 & $177(8)$ \\
\hline $\mathrm{H} 1$ & 0.88270 & 0.68360 & 0.95580 & 1.000 & \\
\hline $\mathrm{H} 2$ & 0.72970 & 0.83370 & 0.85550 & 1.000 & \\
\hline $\mathrm{H} 3$ & 0.69380 & 0.72880 & 0.65570 & 1.000 & \\
\hline $\mathrm{H} 4$ & 0.62410 & 0.52030 & 0.67590 & 1.000 & \\
\hline H5 & 0.29020 & 0.52030 & 0.86380 & 1.000 & \\
\hline H6 & 0.23640 & 0.53680 & 0.76380 & 1.000 & \\
\hline $\mathrm{H} 7$ & -0.04380 & 1.12040 & $1 \cdot 16000$ & 1.000 & \\
\hline H8 & -0.00440 & 1.06240 & 0.98000 & 1.000 & \\
\hline H9 & $0 \cdot 17630$ & 0.87130 & 0.60350 & 1.000 & \\
\hline $\mathrm{H} 10$ & 0.36640 & $0 \cdot 88110$ & 0.60310 & 1.000 & \\
\hline $\mathrm{H} 11$ & 0.41840 & 0.51760 & 0.48280 & 1.000 & \\
\hline $\mathrm{H} 12$ & 0.55200 & 0.67930 & 0.53880 & 1.000 & \\
\hline
\end{tabular}

$U_{\mathrm{eq}}$ is defined as one-third of the trace of the orthogonalized $U_{\mathrm{ij}}$ tensor. 
Table 4. Anisotropic thermal parameters $\left(\AA^{2} \times 10^{4}\right)$.

\begin{tabular}{lrrrrrr}
\hline Atom & $U_{11}$ & $U_{22}$ & $U_{33}$ & \multicolumn{1}{c}{$U_{23}$} & \multicolumn{1}{c}{$U_{13}$} & \multicolumn{1}{c}{$U_{12}$} \\
\hline $\mathrm{Ca}$ & $126(8)$ & $209(9)$ & $178(9)$ & $0(9)$ & $3(9)$ & $-7(9)$ \\
$\mathrm{Sr}$ & $126(8)$ & $209(9)$ & $178(9)$ & $0(9)$ & \multicolumn{1}{c}{$3(9)$} & \multicolumn{1}{c}{$-7(9)$} \\
01 & $149(35)$ & $313(40)$ & $166(42)$ & $-29(36)$ & $-2(35)$ & $46(35)$ \\
02 & $165(38)$ & $359(53)$ & $297(50)$ & $21(38)$ & $-24(36)$ & $-60(35)$ \\
03 & $160(37)$ & $228(43)$ & $207(42)$ & $-62(32)$ & $-43(32)$ & $70(29)$ \\
04 & $163(42)$ & $167(39)$ & $328(48)$ & $-78(32)$ & $-76(34)$ & $-84(31)$ \\
05 & $178(39)$ & $197(39)$ & $294(51)$ & $-93(35)$ & $-11(35)$ & $98(50)$ \\
06 & $154(36)$ & $148(35)$ & $362(53)$ & $6(38)$ & $109(40)$ & $-1(30)$ \\
07 & $529(66)$ & $198(46)$ & $932(92)$ & $-55(57)$ & $-112(79)$ & $98(50)$ \\
08 & $373(53)$ & $334(52)$ & $506(69)$ & $-162(45)$ & $40(49)$ & $46(42)$ \\
09 & $244(44)$ & $491(57)$ & $254(46)$ & $-165(46)$ & $27(35)$ & $3(45)$ \\
010 & $680(78)$ & $557(73)$ & $637(88)$ & $-153(59)$ & $-311(68)$ & $212(61)$ \\
$\mathrm{C} 1$ & $218(57)$ & $108(49)$ & $274(69)$ & $51(46)$ & $56(52)$ & $76(48)$ \\
$\mathrm{C} 2$ & $59(49)$ & $218(58)$ & $240(56)$ & $65(40)$ & $72(42)$ & $-15(39)$ \\
$\mathrm{C} 3$ & $154(50)$ & $63(50)$ & $142(50)$ & $61(37)$ & $-8(38)$ & $58(37)$ \\
$\mathrm{C} 4$ & $156(52)$ & $257(66)$ & $120(57)$ & $-99(42)$ & $-17(44)$ & $-27(43)$ \\
\hline
\end{tabular}

The anisotropic displacement factor exponent takes the form $-2 \pi^{2}\left[\left(h a^{*}\right)^{2} U_{11}+\ldots+2 h k a^{*} b^{*} U_{12}\right]$.

Table 5. Interatomic distances (§) in strontium doped calcium tartrate tetra hydrate.

\begin{tabular}{|c|c|}
\hline $\mathrm{Ca}(\mathrm{Sr})-06$ & $2 \cdot 407(7)$ \\
\hline $\mathrm{Ca}(\mathrm{Sr})-\mathrm{O} 5$ & $2.436(8)$ \\
\hline $\mathrm{Ca}(\mathrm{Sr})-\mathrm{O} 2$ & $2.441(9)$ \\
\hline $\mathrm{Ca}(\mathrm{Sr})-\mathrm{O} 7$ & $2.461(8)$ \\
\hline $\mathrm{Ca}(\mathrm{Sr})-\mathrm{O} 4$ & $2.498(8)$ \\
\hline $\mathrm{Ca}(\mathrm{Sr})-\mathrm{O} 1$ & $2.499(7)$ \\
\hline $\mathrm{Ca}(\mathrm{Sr})-\mathrm{O} 9$ & $2.516(9)$ \\
\hline $\mathrm{Ca}(\mathrm{Sr})-\mathrm{O} 3$ & $2 \cdot 561(8)$ \\
\hline $\mathrm{O} 1-\mathrm{Cl}$ & $1.236(14)$ \\
\hline $\mathrm{O} 2-\mathrm{C} 1$ & $1 \cdot 249(14)$ \\
\hline $\mathrm{O} 3-\mathrm{C} 2$ & $1 \cdot 377(13)$ \\
\hline $\mathrm{O} 3-\mathrm{Ca}(\mathrm{Sr})$ & $2.561(8)$ \\
\hline $\mathrm{O} 3-\mathrm{H} 1$ & $1 \cdot 103(8)$ \\
\hline $\mathrm{O} 4-\mathrm{C} 3$ & $1.408(12)$ \\
\hline $\mathrm{O} 4-\mathrm{Ca}(\mathrm{Sr})$ & $2.498(8)$ \\
\hline $\mathrm{O} 4-\mathrm{H} 4$ & $0.565(8)$ \\
\hline O5-C4 & $1 \cdot 233(13)$ \\
\hline $\mathrm{O} 6-\mathrm{C} 4$ & $1 \cdot 263(13)$ \\
\hline O7-H5 & $1.044(11)$ \\
\hline 07-H6 & $0.837(13)$ \\
\hline $\mathrm{O} 8-\mathrm{H} 7$ & $1.046(10)$ \\
\hline $\mathrm{O} 8-\mathrm{H} 8$ & $1 \cdot 170(10)$ \\
\hline O9-H9 & $0.630(9)$ \\
\hline $\mathrm{O} 9-\mathrm{H} 10$ & $1 \cdot 385(8)$ \\
\hline $\mathrm{O} 10-\mathrm{H} 11$ & $1.059(11)$ \\
\hline $\mathrm{C} 1-\mathrm{O} 2$ & $1 \cdot 249(12)$ \\
\hline $\mathrm{C} 1-\mathrm{C} 2$ & $1.563(15)$ \\
\hline $\mathrm{C} 2-\mathrm{C} 3$ & $1.530(15)$ \\
\hline $\mathrm{C} 2-\mathrm{H}_{2}$ & $1 \cdot 104(10)$ \\
\hline C3-C4 & $1.562(14)$ \\
\hline $\mathrm{C} 3-\mathrm{H} 3$ & $1.060(10)$ \\
\hline C4-O5 & $1.233(13)$ \\
\hline C4-C3 & $1.562(14)$ \\
\hline
\end{tabular}

when compared with calcium tartrate (Hawthorne et al 1982). The crystal structure is shown in figure 4 . Atomic coordinates and anisotropic thermal displacement parameters are given in tables 3 and 4 , respectively. Inter-
Table 6. Selected bond angles (degrees).

\begin{tabular}{lc}
\hline $\mathrm{C} 2-\mathrm{O} 3-\mathrm{H} 1$ & $103 \cdot 8(7)$ \\
$\mathrm{C} 3-\mathrm{O} 4-\mathrm{H} 4$ & $115 \cdot 8(10)$ \\
$\mathrm{H} 5-\mathrm{O} 7-\mathrm{H} 6$ & $77 \cdot 0(9)$ \\
$\mathrm{H} 7-\mathrm{O} 8-\mathrm{H} 8$ & $131 \cdot 7(10)$ \\
H9-O9-H10 & $116 \cdot 2(11)$ \\
$\mathrm{H} 11-\mathrm{O} 10-\mathrm{H} 12$ & $104 \cdot 2(9)$ \\
O1-C1-C2 & $121 \cdot 1(10)$ \\
O3-C2-C1 & $110 \cdot 5(9)$ \\
C1-C2-H2 & $95 \cdot 7(9)$ \\
C1-C2-C3 & $110 \cdot 8(8)$ \\
O3-C2-H2 & $119 \cdot 5(9)$ \\
O3-C2-C3 & $111 \cdot 7(8)$ \\
C3-C2-H2 & $107 \cdot 5(9)$ \\
O4-C3-C2 & $112 \cdot 9(8)$ \\
C2-C3-H3 & $113 \cdot 8(9)$ \\
O4-C3-H3 & $112 \cdot 8(9)$ \\
O7-H5-H6 & $43 \cdot 6(7)$ \\
O7-H6-H5 & $59 \cdot 4(8)$ \\
\hline
\end{tabular}

atomic distances, selected bond angles and hydrogen bond lengths are given in tables 5-7. The metal ion is coordinated by eight oxygens forming a distorted Siamese dedicahydron (Johnson 1966). The water molecule connects tartrate motifs by hydrogen bonding hence forming an infinite chain which runs along the a-axis. The adjacent chains are linked along $b$-axis by the metal and tartrate oxygen bonds. We conclude from this study that the packing of tartrate molecules remains unaltered with $12 \%$ of the strontium doping. Details of the tartrate molecule are shown in figure 5 .

\section{Conclusion}

The silica gel growth system involves the use of calcium chloride and strontium chloride as the top reactants and sodium meta silicate impregnated with tartaric acid as 
Table 7. Hydrogen bonds.

\begin{tabular}{|c|c|c|c|c|}
\hline A-H ...B & $\mathbf{A}-\mathrm{H}$ & $\mathrm{B}$ & H ...B & A-H ...B \\
\hline $\mathrm{O} 4-\mathrm{H} 4 \ldots \mathrm{O} 10$ & $0.565(8)$ & $2 \cdot 725(15)$ & $2 \cdot 211(13)$ & $152 \cdot 5(8)$ \\
\hline $\mathrm{O} 7-\mathrm{H} 5 \ldots \mathrm{O} 1$ & $1.044(11)$ & $3.077(13)$ & $2.816(8)$ & $94 \cdot 4(5)$ \\
\hline $\mathrm{O} 8-\mathrm{H} 8 \ldots \mathrm{O} 2$ & $1 \cdot 170(10)$ & $3 \cdot 261(13)$ & $2.833(9)$ & $100 \cdot 8(5)$ \\
\hline O8-H8 ... O6 & $1 \cdot 170(10)$ & $2 \cdot 887(14)$ & $1.738(9)$ & $166 \cdot 0(6)$ \\
\hline O9-H9 ... O5 & $0.630(9)$ & $2 \cdot 882(11)$ & $2.551(8)$ & $115 \cdot 8(9)$ \\
\hline O9-H10 ...O1 & $1 \cdot 385(8)$ & $3 \cdot 194(11)$ & $2 \cdot 584(8)$ & $103 \cdot 0(4)$ \\
\hline $\mathrm{O} 3-\mathrm{H} 1 \ldots \mathrm{O} 2$ & $1 \cdot 103(7)$ & $2 \cdot 596(11)$ & $1.522(8)$ & $162 \cdot 8(5)$ \\
\hline O3-H1 .. O5 & $1 \cdot 103(7)$ & $3-266(11)$ & $2.758(8)$ & $107 \cdot 6(5)$ \\
\hline
\end{tabular}

lower reactant results in the crystallization of calcium strontium tartrate with the molecular formula $\mathrm{Ca}_{0.88} \mathrm{Sr}_{0.12} \mathrm{C}_{4} \mathrm{H}_{4} \mathrm{O}_{6} \cdot 4 \mathrm{H}_{2} \mathrm{O}$. The optical transition range has been determined from the UV-visible spectra for CST which extends from $275 \mathrm{~nm}$ to $1400 \mathrm{~nm}$. This makes the CST material interesting for second harmonic generation in the UV region. The optical characteristics of CST crystal is found to be positive. CST exhibits optical nonlinearity. From the structural study, it is found that the packing of tartrate molecules remains unaltered with $12 \%$ of strontium doping in CST.

\section{Acknowledgement}

We thank Prof. T N Guru Row, Solid State and Structural Chemistry Unit, Indian Institute of Science, Bangalore, for providing facilities to carry out the structural work of material.

\section{References}

Ambady G K 1968 Acta Crystallogr. B24 1548

Bohandy J and Murphy J C 1968 Acta Crystallogr. B24 286

Brehat F and Wyncke B 1989 J. Phys. B: At. Mol. Opt. Phys. 221981

Hawthorne F C, Borys I and Ferguson R B 1982 Acta Cryst. B38 2461

Johnson N W 1966 Canadian J. Math. 18169

Medrano C, Gunter P and Arend H 1987 Phys. Status Solidi (b)14B 749

Nakatani N 1991 Jap. J. Appl. Phys. 301961

Rethinam F J, Arivuoli D, Ramasamy S and Ramasamy P 1994 Mater. Res. Bull. 29309

Selvarajan P, Has, B N Gon and Rao K V 1993 J. Mater. Sci. Letts 121210

Sheldrick G M 1985 SHELXS 86, program for the solution of crystal structures (Germany: Univ. of Gottingen)

Sheldrick G M 1993 SHELXL 93, program for the refinement of crystal structures (Germany: Univ. of Gottingen) 